\title{
Aggregate Implications of Heterogeneous Households in a Sticky-Price Model
}

\author{
Jae Won Lee* \\ Rutgers University
}

August 15, 2008 (First draft)

August 18, 2011 (This version)

\begin{abstract}
This paper analyzes the role of heterogeneous households in propagating shocks over the business cycle by generalizing a basic sticky-price model to allow for imperfect risksharing between households that differ in labor incomes. I show that imperfectly insured household consumption distorts household incentive to supply labor hours through an idiosyncratic income effect, which in turn generates strategic complementarities in price setting and thus amplifies business cycle fluctuations. This mechanism diminishes the role of nominal rigidities and makes sticky-price models more consistent with microeconomic evidence on the frequency of price changes.
\end{abstract}

JEL codes: E13, E31, E32, E44

Keywords: heterogeneity, price stickiness, consumption insurance, real rigidity, strategic complemetarity, Phillips curve

*I would like to thank Chris Sims, Nobuhiro Kiyotaki, Ricardo Reis, Sam Schulhofer-Wohl, Lars Svensson, Per Krusell, Roberto Chang, Bruce Mizrach, John Landon-Lane, Yongsung Chang, Tack Yun, Jinil Kim, Jonathan Heathcote, Carlos Carvalho, Harold Cole, Dirk Krueger, Jae Sim, and Woong Yong Park. I have benefited from comments by Paul Evans (the editor) and two anonymous referees. A version of this paper was presented at Princeton, Rutgers, Ohio State, Indiana, U-Conn, UC-Davis, Georgetown, FRB-Boston and the Federal Reserve Board. I thank numerous seminar participants for helpful comments and discussions. I thank the Sidney Simon Grant and the Rutgers Research Council Grant for financial help. 


\section{Introduction}

The first generation of dynamic stochastic general equilibrium (DSGE) models, best exemplified by Kydland and Prescott (1982) and King, Plosser and Rebelo (1988), assumed away heterogeneity among households. Over the past two decades, a large body of literature has investigated how heterogeneous households can affect the aggregate dynamics of equilibrium prices and quantities. ${ }^{1}$ However, most important works in this literature assume that prices are fully flexible, precluding consideration of the aggregate effects of household heterogeneity via nominal rigidities. To address this, I take an otherwise standard sticky-price model (also known as a New Keynesian model), one of the workhorse models for the analysis of monetary policy and business cycles, and introduce heterogeneous households. ${ }^{2}$ I propose a novel mechanism through which household heterogeneity affects the equilibrium dynamics of aggregate output and price nontrivially. Specifically, this paper shows imperfectly insured household consumption affects the household incentive to supply labor hours through an idiosyncratic income effect, which in turn generates "real rigidities" and thus amplifies business cycle fluctuations.

This paper develops a tractable sticky-price model with heterogeneous households and financial frictions. The model developed here nests the basic New Keynesian (NK) model in Woodford (2003, ch. 3), which makes it possible to compare the two models within a unified framework. As in the basic NK model, households differ in labor income because each has a specialized labor skill and hence is employed in a different industry. Unlike the basic model, however, households cannot perfectly insure against idiosyncratic labor income risks because there are costs in moving resources between households, which I refer to as

\footnotetext{
${ }^{1}$ This research agenda is relatively young, but is growing rapidly, partly due to the development of faster computing machines. Important early contributions include Huggett (1993), Aiyagari (1994), Krusell and Smith (1998), and many other articles cited in the review paper by Heathcote et al.(2009).

${ }^{2}$ The standard sticky-price models (or New Keynesian models) are extensively discussed in many graduate level textbooks such as Woodford (2003), Walsh (2003), and Gali (2008), and also in an earlier paper by Goodfriend and King (1997). See Christiano et al. (2005) and Smet and Wouters (2003, 2007) for leading examples of medium-scale sticky-price DSGE models. In this paper, I use the two terms, "sticky-price models" and "New Keynesian (NK) models" interchangeably.
} 
"financial frictions" in this paper. ${ }^{3}$ Financial frictions lead to a smaller wage elasticity of each household labor supply through an "income effect" channel: other things being equal, a rise in the real wage of an industry increases household consumption in that industry, which in turn reduces household incentive to supply labor hours. Due to the less elastic labor supply, firms face steeper marginal cost schedules, which in turn generates a strategic complementarity in firms' price settings and subsequently makes the short-run Phillips curve flatter. In contrast, the "income effect" channel is absent in representative-household models because household consumption levels are equalized through costless trading of state-contingent assets and hence an idiosyncratic change in labor income does not affect household consumption.

An important implication is that sticky-price models can be made more consistent with microeconomic evidence on frequent price adjustments. Household heterogeneity amplifies the persistence and variability of the output gap through the mechanism described above and thus diminishes the role of nominal rigidities as a source of propagating economic shocks. As a consequence, the degree of nominal rigidities required to explain the observed persistence and variability of the U.S. output gap is significantly reduced relative to the basic NK model.

The paper is organized as follows. After discussing the related literatures, I present the model and the main theoretical result in Section 2. Section 3 presents reduced-form equations that characterize the equilibrium dynamics of key aggregate variables and relates the model to an alternative NK model with rule-of-thumb consumers and asset market segmentation. Section 4 documents the consequences of introducing household heterogeneity for the inference about the frequency of price changes. Section 5 summarizes the results and concludes.

Related Literature This paper fits well into the growing literature on the aggregate implications of including heterogeneous households in macroeconomic models and the literature on real rigidities. This paper builds a bridge between these two active research areas by show-

\footnotetext{
${ }^{3}$ Woodford's basic NK model features industry-specific labor markets, and households work in different industries, which makes households heterogeneous in labor income. However, the household heterogeneity becomes irrelevant as household consumption levels are identical under complete asset markets. Therefore the basic model is essentially a representative-household model. I refer the reader to Woodford (2003, page 144-146) for a detailed discussion.
} 
ing household heterogeneity (due to financial frictions) can be an important source of real rigidities, through its impact on the household labor supply, and thus can nontrivially affect aggregate dynamics.

One of the earliest works that emphasize the importance of real rigidities in business cycles is Ball and Romer (1990). Subsequently, Altig et al. (2010), Kimball (1995), Bergin and Feenstra (2000), Basu (1995) and Carvalho (2006) showed that there are different ways to generate stronger real rigidities, such as firm-specific capital, non-CES utility, intermediate inputs, decreasing returns to scale technology, and multiple sectors. However, up to my knowledge, this paper is the first study that finds there is an economic linkage between imperfect risk-sharing among heterogeneous households, income effects on labor supply and real rigidities. While it may be interesting to investigate the relative merits of the different sources of strategic complementarities and real rigidities, that is not what this paper is about. There is ample evidence that asset markets are less than ideal and that household consumption often moves in response to an income fluctuation (Nelson, 1994; Attanasio and Davis, 1996; Hayashi et. al., 1996). Motivated by the evidence, this paper is focused on studying the new mechanism in isolation and assessing the importance of the real rigidities marginally contributed by household heterogeneity if the degree of frictions in risk-sharing is parameterized based on micro evidence on co-movement between household consumption and income. ${ }^{4}$

Bils and Klenow (2004) recently documented that firms update their prices less than every 2 quarters on average. ${ }^{5}$ Their finding suggests an inconsistency between macro-model specifications and micro-level empirical evidence. At the macro level, sticky-price DSGE models often require a large degree of nominal rigidities to generate persistent real effects of shocks and inertial inflation. The estimated frequency of price changes is often less than once every 4 quarters using standard sticky-price models, which is not consistent with Bils and

\footnotetext{
${ }^{4}$ It is also well documented that industry-specific labor markets in the basic NK model generate a strategic complementarity in firms' price decisions and increase real rigidities. What this paper shows is that relaxing the extreme assumption of perfect risk-sharing among workers can make the degree of strategic complementarity even stronger, and this substantially improves the sticky-price models' consistency with micro-level evidence on the frequency of price changes.

${ }^{5}$ Nakamura and Steinsson (2008) have also found a similar result in the case that temporary sales are not excluded.
} 
Klenow's finding based on micro level data. ${ }^{6}$ This paper shows that household heterogeneity generates strategic complementarities strong enough to reconcile the inconsistency. ${ }^{7}$

Bernanke et al. (1999), in their seminal paper, showed that financial frictions amplify the real impact of a policy shock through the financial-accelerator mechanism in a stickyprice model. This paper proposes another channel through which financial frictions affect real sectors in a sticky-price framework, focusing on a different consequence on economic agents of financial market imperfections.

\section{Model}

This section describes the model economy. The model is similar to the basic NK model with industry-specific labor markets in Woodford (2003). The only deviation from the basic model is the existence of a cost of transferring resources among households, as in Schulhofer-Wohl (2010). As a result, households are not able to insure their income risks perfectly. The model nests the basic NK model as a special case, which makes it possible to compare the perfect and imperfect risk-sharing economies within a single framework.

\subsection{Households}

There is a continuum of industries indexed by $i \in[0,1]$, each of which specializes in a different type of good. Each of the differentiated goods requires a distinct labor skill to be produced; that is, labor markets are industry-specific.

Households are heterogeneous in labor skills and hence in labor incomes. Type- $i$ household possesses a labor skill that produces type- $i$ good, and thus supplies labor hours in industry $i$

\footnotetext{
${ }^{6}$ See Altig et al. (2010) for a discussion on the inconsistency between microeconomic data and macroeconomic models.

Chari et al. (2000) have stressed the importance of "endogenous stickiness", arguing that sticky-price models need to amplify price stickiness endogenously to explain persistent aggregate dynamics with a reasonable degree of nominal rigidity.

${ }^{7}$ In the same spirit, some authors recently explored whether introducing firm-specific capital can reduce model-implied nominal rigidities to the point that the inconsistency is reconciled. See Altig et al. (2010), Eichenbaum and Fisher (2007), and Woodford (2005) for examples.
} 
only. It maximizes the following discounted expected utility function:

$$
E_{0}\left(\sum_{t=0}^{\infty} \beta^{t}\left[\frac{C_{t}(i)^{1-\sigma}-1}{1-\sigma}-\frac{H_{t}(i)^{1+\frac{1}{\psi}}}{1+\frac{1}{\psi}}\right]\right)
$$

where $C_{t}(i)$ denotes type- $i$ household's consumption, and $H_{t}(i)$ denotes the hours of labor services supplied to industry $i$. The parameters, $\beta \in(0,1), \psi \geq 0$, and $\sigma \geq 0$ stand for, respectively, the discount factor, the Frisch elasticity of labor supply, and the coefficient of relative risk aversion.

A household's dynamic budget constraint is given by

$$
P_{t} C_{t}(i)+E_{t}\left[Q_{t, t+1} B_{t+1}(i)\right]+P_{t} \underbrace{\phi \Phi\left(C_{t}(i), X_{t}(i)\right)}_{\text {real transaction cost }}=B_{t}(i)+W_{t}(i) H_{t}(i)+\Pi_{t}-P_{t} T_{t},
$$

where $P_{t}$ denotes aggregate price level, $W_{t}(i)$ is the competitive nominal wage rate in industry $i, T_{t}$ is a lump-sum tax, $\Pi_{t}$ is the aggregate nominal profit of the economy, and $X_{t}(i)$ denotes a household's total after-tax real income at time $t$, which is given by the sum of labor and profit incomes net of taxes:

$$
X_{t}(i) \equiv \frac{W_{t}(i) H_{t}(i)+\Pi_{t}-P_{t} T_{t}}{P_{t}}
$$

Unlike labor income, neither profit income nor tax is idiosyncratic. Two implicit simplifying assumptions are that every household holds the same mutual fund so that the economy's total profit is equally distributed among households, and that the government collects the same amount of lump-sum tax from each household. Consequently, the income differential between any two households is entirely due to a difference in labor income.

Households can trade nominal securities with arbitrary patterns of state-contingent payoffs. In the budget constraint, $B(i)$ denotes type- $i$ household's holding of one period statecontingent nominal securities, and $Q_{t, t+1}$ is a stochastic discount factor. When households make their portfolio decision at time $t$, they completely specify the desired revenue for each 
possible state $\left(B_{t+1}(i)\right)$ taking the market prices for the state-contingent payoffs as given. Thus $B_{t+1}(i)$ is a random variable that can have different values depending on the state realized at time $t+1$.

Making consumption different from income is costly. If a household's consumption $C_{t}(i)$ is different from its period income $X_{t}(i)$ then the cost is the amount $\phi \Phi(C(i), X(i))$ of consumption good, where $\phi \geq 0$. Following Schulhofer-Wohl (2010), I set some restrictions on the transaction cost function $\Phi(\cdot): \Phi(C(i), X(i))=0$ if $C(i)=X(i)$ and $\Phi(C(i), X(i))>0$ otherwise; $\Phi$ is convex and twice differentiable with $\partial^{2} \Phi / \partial C(i) \partial X(i)<0$. I further assume that the function $\Phi(\cdot)$ has the following form:

$$
\Phi(C, X)=\frac{C}{2}\left(\log \frac{C}{X}\right)^{2}
$$

Note that any functions that satisfy the stated assumptions on $\Phi$ would lead us to the same results. An important special case arises when $\phi=0$. The model presented here is then the same as the basic NK model.

There are certainly other ways to introduce imperfect asset markets in macroeconomic models. For example, one of the standard approaches in the literature is to assume there exists only one financial security, a short-term riskless bond. In contrast, this model has a full set of state-contingent assets. The transaction cost, however, causes households to insure their income risks by a lesser degree than they would in a "frictionless complete market economy", which leads to less than ideal risk-sharing.

Although this paper's approach, that features a combination of a full set of state-contingent assets and the particular transaction cost, may seem less conventional, it has some advantages besides the obvious benefit of providing a straightforward way to nest the basic NK model as a special case within a single framework. Reality suggests a multiplicity of risk-sharing institutions as well as of sources of financial frictions, and including a full set of state-contingent assets together with a reduced-form transaction cost in a model is a convenient way to in- 
corporate the multiplicity. ${ }^{8}$ On the one hand, considering the variety of financial securities being traded in the markets nowadays as well as the non-market institutions that households use to share risk, models with complete asset markets are perhaps not far from reality and probably more realistic than models with a riskless bond only. On the other hand, it is well documented that consumption insurance is not perfect, and the partial insurance can stem from various sources: borrowing constraints, trading costs, imperfect information and limited commitment. ${ }^{9}$ The transaction cost is intended to capture all such "financial frictions" as a reduced form and to allow me to focus on the main research question of this paper without having to consider details of asset market imperfections, which is less important for the purpose of this paper. The main insights of this paper are not conditional on the particular model of asset markets I adopt: the results generalize to other asset market institutions that make household consumption covary with household labor income. ${ }^{10}$ Hence this paper does not attempt to provide micro-foundations of the transaction cost.

A household's optimality conditions are:

$$
\begin{gathered}
\beta \frac{P_{t} C_{t}(i)^{\sigma}\left\{1+\phi \Phi_{C}\left(C_{t}(i), X_{t}(i)\right)\right\}}{P_{t+1} C_{t+1}(i)^{\sigma}\left\{1+\phi \Phi_{C}\left(C_{t+1}(i), X_{t+1}(i)\right)\right\}}=Q_{t, t+1}, \\
H_{t}(i)^{\frac{1}{\psi}} C_{t}(i)^{\sigma} \frac{\left\{1+\phi \Phi_{C}\left(C_{t}(i), X_{t}(i)\right)\right\}}{\left\{1-\phi \Phi_{X}\left(C_{t}(i), X_{t}(i)\right)\right\}}=\frac{W_{t}(i)}{P_{t}},
\end{gathered}
$$

where $\Phi_{C}$ and $\Phi_{X}$ are the partial derivatives of $\Phi(\cdot)$ with respect to the level of consumption and income:

$$
\Phi_{C} \equiv \frac{\partial \Phi}{\partial C}=\left(\log \frac{C(i)}{X(i)}\right)+\frac{1}{2}\left(\log \frac{C(i)}{X(i)}\right)^{2}
$$

\footnotetext{
${ }^{8}$ I am very sympathetic to Schulhofer-Wohl (2010)'s view that:

"I interpret the transactions costs (with complete asset markets) in my model as a reduced form for all of the institutions that households use to share risk and all of the information and incentive problems that make these institutions less than ideal."

${ }^{9}$ See Nelson (1994), Attanasio and Davis (1996) and Hayashi et. al. (1996) for important empirical contributions.

${ }^{10}$ In a companion paper, Lee (2010) obtains the same results using a NK model that features only riskless bonds and a bond adjustment cost similar to the one employed in Heathcote and Perri (2002) and SchmittGrohe and Uribe (2003). In particular, Lee (2010) shows that the log-linearized reduced form of the model is same as the one developed in this paper.
} 


$$
\Phi_{X} \equiv \frac{\partial \Phi}{\partial X}=-\frac{C(i)}{X(i)}\left(\log \frac{C(i)}{X(i)}\right)
$$

The gross nominal interest rate $R_{t}$ is determined by $R_{t}^{-1}=E_{t}\left[Q_{t, t+1}\right]$ because $R_{t}^{-1}$ is the price of a portfolio in which $B_{t+1}(i)=1$ for every state of the economy at time $t+1$. The equation $R_{t}^{-1}=E_{t}\left[Q_{t, t+1}\right]$ and (1) together yield a consumption Euler equation:

$$
R_{t}^{-1}=\beta E_{t}\left[\frac{P_{t} C_{t}(i)^{\sigma}\left\{1+\phi \Phi_{C}\left(C_{t}(i), X_{t}(i)\right)\right\}}{P_{t+1} C_{t+1}(i)^{\sigma}\left\{1+\phi \Phi_{C}\left(C_{t+1}(i), X_{t+1}(i)\right)\right\}}\right] .
$$

It is straightforward to show that, in the special case of no financial frictions (i.e. $\phi=0$ ), the economy is characterized by perfect consumption insurance, in which case one can assume, without affecting aggregate equilibrium, there exists a representative household who supplies all types of labor. Using a normalizing assumption on the distribution of households' initial wealth, one obtains from (1) that

$$
C_{t}(i)=C_{t}(j)=Y_{t}, \quad \forall i, j \in[0,1]
$$

which should hold for every time period $t$ and also for every possible state of the economy. Note $Y_{t}$ denotes aggregate output. In this case, the first-order condition for supply of type- $i$ labor, (2), can be rearranged into the familiar expression:

$$
H_{t}(i)^{\frac{1}{\psi}} Y_{t}^{\sigma}=\frac{W_{t}(i)}{P_{t}}
$$

It is helpful to compare (2) to (5) in developing an intuition for the economic mechanism through which imperfect risk-sharing affects aggregate dynamics. With financial frictions (i.e. $\phi>0$ ), a household's consumption, $C_{t}(i)$ in (2), depends positively on labor income, and thus on the real wage $\frac{W_{t}(i)}{P_{t}}$ and labor hours $H_{t}(i)$. As a household's labor income increases, its consumption level also rises, and consequently the household has less incentive to supply more labor hours. In other words, the wage elasticity of a household's labor supply is effectively 
smaller than the standard Frisch elasticity indicates due to the income effect. ${ }^{11}$ Since a less elastic labor supply curve implies a steeper marginal cost schedule for a firm, prices adjust more slowly. In contrast, there is no such income effect in the case of perfect risk-sharing because households can completely insure against income risk: a change in $\frac{W_{t}(i)}{P_{t}}$ or $H_{t}(i)$ does not affect type- $i$ household's consumption, $Y_{t}$ in (5).

As an example, suppose type- $i$ firm considers lowering its price because a positive technology shock has decreased its marginal cost. Lowering the price in turn leads to a higher demand for type- $i$ firm's good; a higher demand for type- $i$ labor (i.e. the labor demand curve shifts out); an increase in the wage rate for type- $i$ labor and thus type- $i$ firm's marginal cost. As the later increase in marginal cost will partly offset the initial decrease in marginal cost due to the shock, the firm's incentive to lower its price diminishes. However, the later increase in marginal cost (real wage) is bigger when the labor supply is inelastic, and thus, when there are financial frictions, type- $i$ firm's price will not adjust as much as it would otherwise. Since every firm experiences this, the aggregate price level adjusts more slowly in response to a shock. This is a classic example of "real rigidities." As will be seen later, this effect is captured by a flatter Phillips curve.

The equilibrium conditions can be log-linearized around the symmetric non-stochastic steady state. ${ }^{12}$ The log-linear approximations of (1), (2) and (3) are respectively:

$$
\begin{gathered}
c_{t}(i)=c_{t+1}(i)+\frac{1}{\sigma+\phi}\left(q_{t, t+1}+\pi_{t+1}\right)+\frac{\phi}{\sigma+\phi}\left(x_{t}(i)-x_{t+1}(i)\right), \\
w_{t}(i)-p_{t}=\frac{1}{\psi} h_{t}(i)+\sigma c_{t}(i)
\end{gathered}
$$

${ }^{11}$ Note that the marginal rate of substitution,

$$
M R S_{t}(i) \equiv H_{t}(i)^{\frac{1}{\psi}} C_{t}(i)^{\sigma} \frac{\left\{1+\phi \Phi_{C}\left(C_{t}(i), X_{t}(i)\right)\right\}}{\left\{1-\phi \Phi_{X}\left(C_{t}(i), X_{t}(i)\right)\right\}}
$$

is an increasing function of $C_{t}(i)$. In turn, $C_{t}(i)$ is an increasing function of $X_{t}(i)$ and thus of $H_{t}(i)$ and $W_{t}(i) / P_{t}$. Since $M R S_{t}(i)=W_{t}(i) / P_{t}$ in equilibrium, it can be easily shown that supply of labor hours $H_{t}(i)$ responds less to a change in the real wage $W_{t}(i) / P_{t}$.

${ }^{12}$ In the absence of shocks, households and firms are symmetric as in the basic NK model. In consequence, the model developed here has the same steady state equilibrium as the basic NK model, and thus its derivation is omitted for brevity. 


$$
c_{t}(i)=E_{t} c_{t+1}(i)-\frac{1}{\sigma+\phi}\left(r_{t}-E_{t} \pi_{t+1}\right)+\frac{\phi}{\sigma+\phi} E_{t}\left(x_{t}(i)-x_{t+1}(i)\right),
$$

where I use lowercase letters to denote percentage deviations from the steady state. ${ }^{13}$

From (6), one can derive an analytical expression for a household's consumption as a weighted average of the household's idiosyncratic income and aggregate income: ${ }^{14}$

$$
c_{t}(i)=\frac{\omega}{1+\omega} x_{t}(i)+\left(1-\frac{\omega}{1+\omega}\right) y_{t},
$$

where the parameter, $\omega$ is the ratio of transaction cost to risk aversion:

$$
\omega \equiv \phi / \sigma
$$

and, as mentioned earlier, $y_{t}$ denotes aggregate output/income, which is equal to aggregate consumption, $\int_{0}^{1} c_{t}(i) d i$, in equilibrium.

An alternative way to write (9) is:

$$
c_{t}^{R}(i)=\frac{\omega}{1+\omega} x_{t}^{R}(i) .
$$

The variables with superscript $R, c_{t}^{R}(i)$ and $x_{t}^{R}(i)$, denote respectively $c_{t}(i)-y_{t}$ and $x_{t}(i)-$ $y_{t}$ : type- $i$ household's consumption and after-tax real income relative to aggregate income. Equation (10) indicates that a household's relative consumption moves in the same direction with its relative income as long as $\phi$ (and thus $\omega$ ) is positive. It is easy to verify that, when $\phi=0$, the model is characterized by perfect risk-sharing (i.e. $c_{t}^{R}(i)=0$ ) and consequently becomes identical to the basic NK model with a representative household.

Using micro level data, Schulhofer-Wohl (2010) estimated $\omega$, the ratio of transaction cost to risk aversion, and showed that a reasonable value of $\omega$ should be in the range of 0.117-0.205 if heterogeneous preferences among households were taken into account. If households are

\footnotetext{
${ }^{13}$ For example, $c_{t}(i) \equiv \log C_{t}(i)-\log C$, where $C$ is a common steady state level of consumption of households.

${ }^{14}$ See appendix for a derivation.
} 
assumed to have identical preferences, as in this paper, Schulhofer-Wohl argued the estimated $\omega$ can be as large as 0.54 . In this paper, I use 0.2 as the benchmark value for $\omega,{ }^{15}$ but also consider other values in the neighborhood of 0.2 . At $\omega=0.2$, a one percent increase in income raises consumption by 0.167 percent. $^{16}$

\section{$2.2 \quad$ Firms}

This subsection describes the production side of the economy. Each industry $i$ has a representative firm called type- $i$ firm that produces a distinct type of good $Y_{t}(i)$. Type- $i$ firm's production function is:

$$
Y_{t}(i)=A_{t} H_{t}(i)
$$

where $A_{t}$ denotes the level of economy-wide productivity. The final good, $Y_{t}$, which is consumed by households, is produced by perfectly competitive firms assembling the differentiated goods with a Dixit-Stiglitz (1977) production technology: $Y_{t}=\left(\int_{0}^{1} Y_{t}(i)^{\frac{\theta-1}{\theta}} d i\right)^{\frac{\theta}{\theta-1}}$, where $\theta>$ 1. The corresponding price index for the final consumption good is $P_{t}=\left(\int_{0}^{1} P_{t}(i)^{1-\theta} d i\right)^{\frac{1}{1-\theta}}$, where $P_{t}(i)$ is the price of type- $i$ good. The optimal demand for each type of good is obtained as $Y_{t}(i)=\left(\frac{P_{t}(i)}{P_{t}}\right)^{-\theta} Y_{t}$.

As in Calvo (1983) and Yun (1996), firms adjust their prices with probability $1-\alpha$ each period. Consequently, the price level $P_{t}$ evolves as:

$$
P_{t}=\left[\int_{\mathcal{I}^{*}} P_{t}^{*}(i)^{1-\theta} d i+\alpha P_{t-1}^{1-\theta}\right]^{\frac{1}{1-\theta}}
$$

where $\mathcal{I}^{*} \subset[0,1]$, with size of $1-\alpha$, is a randomly chosen subset in which firms update their prices and $P_{t}^{*}(i)$ is an optimal price chosen by firm $i$ where $i \in \mathcal{I}^{*}$. A firm that re-optimizes

\footnotetext{
${ }^{15}$ Schulhofer-Wohl (2010) estimates $\omega$ using two different definitions of "New Household". Roughly, 0.2 is a point estimate of $\omega$ under one of the two definitions. I refer the interested readers to Schulhofer-Wohl (2010) for a detailed discussion of the estimation.

${ }^{16}$ Households in the model are ex-ante identical in their expected incomes. For an illustration, let's assume households earn and consume $\$ 10,000$ per quarter on average (and in the steady state), which is a roughly consistent figure for many developed countries including the US. If a shock raises a household's income unexpectedly by $1 \%$, and thus the household earns an extra $\$ 100$, the benchmark case suggests it would spend an extra $\$ 16.70$ for consumption and save the remaining amount $\$ 83.30$.
} 
at time $t$ chooses $P_{t}^{*}(i)$ to maximize its expected discounted profit:

$$
\max _{P_{t}^{*}(i)} E_{t} \sum_{k=0}^{\infty} \alpha^{k} Q_{t, t+k}\left\{P_{t}^{*}(i) Y_{t+k}(i)-W_{t+k}(i) H_{t+k}(i)\right\}
$$

The optimality condition is:

$$
E_{t} \sum_{k=0}^{\infty} \alpha^{k} Q_{t, t+k}\left(\frac{P_{t}^{*}(i)}{P_{t+k}}\right)^{-\theta} Y_{t+k}\left\{P_{t}^{*}(i)-\left(\frac{\theta}{\theta-1}\right) \frac{W_{t+k}(i)}{A_{t+k}}\right\}=0
$$

Note that there is no need to introduce idiosyncratic shocks to induce heterogeneity in household incomes. When pricing decisions are staggered, aggregate shocks induce idiosyncratic shocks because price adjustments are not synchronized across firms, which creates income dispersions across households. ${ }^{17}$

Loglinearizing (11) and (12), I can obtain the generalized NK Phillips curve that accounts for household heterogeneity and financial frictions, whose effects on aggregate dynamics are entirely captured by the reduced slope.

Proposition 1 (Generalized Short-Run Phillips Curve) Consider the heterogeneoushousehold sticky-price model described in this paper. Aggregate output and inflation must satisfy a Phillips curve (or an aggregate supply curve) of the form:

$$
\pi_{t}=\beta E_{t} \pi_{t+1}+\kappa\left(y_{t}-y_{t}^{N}\right)
$$

where

$$
\begin{aligned}
& \kappa \equiv\left\{\frac{(1-\alpha)(1-\alpha \beta)}{\alpha}\right\}\left\{\frac{\sigma+\psi^{-1}}{1+\theta\left(\psi^{-1}+\sigma \gamma\right)}\right\}, \\
& \gamma \equiv \frac{\omega\left(1+\psi^{-1}\right)}{\frac{\theta-1}{\theta}(1+\omega)-\sigma \omega} .
\end{aligned}
$$

The variable $y_{t}^{N}$ denotes the natural level of output that would arise in the absence of nominal

\footnotetext{
${ }^{17}$ Introducing idiosyncratic shocks would not change the main insights of this paper. See Lee (2010) for a model similar to the current model, but with sector-specific shocks.
} 
rigidities and financial frictions. ${ }^{18}$ Given other parameters (especially the degree of nominal rigidities, $\alpha$ ), the slope of the Phillips curve $\kappa$ gets smaller as the degree of financial frictions $\phi$ (captured in $\omega$ ) gets larger, as long as $\omega<\frac{1}{\left(\frac{\theta}{\theta-1}\right) \sigma-1}$ (or equivalently $\phi<\frac{\sigma}{\left(\frac{\theta}{\theta-1}\right) \sigma-1}$ ).

The proof is outlined in the appendix. The reduced-form of the Phillips curve therefore remains the same as in the basic NK model. However, an additional term, $\sigma \gamma$, is introduced in the denominator of the slope $\kappa$ due to financial frictions. The inequality $\omega<\frac{1}{\left(\frac{\theta}{\theta-1}\right) \sigma-1}$ is a condition that makes $\gamma$ positive and thus makes the slope, $\kappa$ smaller. If this inequality does not hold, the Phillips curve gets steeper. Intuitively, when the degree of financial frictions $\omega($ or $\phi)$ is too large, the income effect is so large that the slope of the labor supply curve becomes negative: households supply fewer labor hours as the real wage increases. Since I view this case as rather unusual, I will focus only on the case in which the degree of financial frictions is non-negative but not too large; i.e. $0 \leq \omega<\frac{1}{\left(\frac{\theta}{\theta-1}\right) \sigma-1}$. Note that the inequality is necessary only when $\sigma>\frac{\theta-1}{\theta}$, because $\gamma$ is always positive, regardless of $\omega$, when $\sigma \leq \frac{\theta-1}{\theta}$. In other words, the income effect would never get too large when $\sigma$ is small.

First consider the special case in which there are no financial frictions and hence households' risk-sharing is perfect (i.e. $\omega=0$ ). The slope of the Phillips curve would be the same as in the basic NK model with a representative household. Another special case arises when households have infinite elasticity of intertemporal substitution (i.e. $\sigma=0$ ). In that case, the slope would be unaffected even if $\omega>0$. The reason is that when $\sigma=0$, household consumption decisions do not affect the marginal rate of substitution, and thus the idiosyncratic income effect on labor supply does not arise. This suggests that elasticity of intertemporal substitution is another key factor that determines the quantitative importance of heterogeneous households in this model.

Except for these two special cases, imperfect risk-sharing generally influences equilibrium aggregate dynamics by making the short-run Phillips curve flatter. Figure 1 plots the slope

\footnotetext{
${ }^{18}$ The natural level of output is given by $y_{t}^{N}=\left(\frac{1+\psi^{-1}}{\sigma+\psi^{-1}}\right) a_{t}$, which is a well-known expression in the literature. Therefore I omit a detailed derivation and refer the interested readers to Woodford (2003) or Gali (2008).
} 
of the Phillips curve, varying the degree of financial frictions, $\omega \cdot{ }^{19}$ For example, if $\sigma=3$ and $\omega=0.2$, the slope is only about one-fourth of the slope under perfect consumption insurance. If a higher value of either $\sigma$ or $\omega$ were used, then the slope would become even smaller. This suggests that the effect on aggregate dynamics of household heterogeneity due to financial frictions can be substantial.

\subsection{Government}

Assuming the government does not issue the state-contingent assets, the government budget constraint is given by

$$
P_{t} G_{t}=P_{t} T_{t}+\int_{0}^{1} \phi \Phi\left(C_{t}(i), X_{t}(i)\right) d i,
$$

where $G_{t}$ is government purchases. For simplicity, I assume the government collects the transaction costs, $\int_{0}^{1} \phi \Phi\left(C_{t}(i), X_{t}(i)\right) d i$, and set $G_{t}=0$ throughout the paper. This leads to simple market clearing conditions:

$$
\int_{0}^{1} C_{t}(i) d i=Y_{t} \quad \text { and } \quad \int_{0}^{1} B_{t}(i) d i=0 .
$$

The first market clearing condition is a resource constraint which can be obtained by integrating all households' and the government's constraints. The second is the market clearing condition for each state-contingent asset. Finally, the model can be closed by a Taylor-type interest rate rule.

\section{Model in Log-Linear Approximation and Discussions}

In the basic NK model with a representative household (and/or complete asset markets), it is well known that only three equations, an IS curve, a Phillips curve, and a monetary policy rule, are necessary to determine equilibrium dynamics of the three key aggregate variables: the

\footnotetext{
${ }^{19}$ For Figure 1 , I set $\beta$ to be $0.99, \sigma$ to be $3, \varphi$ to be $2, \theta$ to be 6 , and $\alpha$ to be 0.5 .
} 
output, inflation and the nominal interest rate, $\left\{y_{t}, \pi_{t}, r_{t}\right\}$, although there are infinitely many other equilibrium conditions because the model has a continuum of firms. The assumption of time dependent pricing, together with the symmetric nature of the model, plays a key role in reducing the number of state variables required to study aggregate variables. Researchers therefore do not need to consider other equilibrium conditions unless they want to analyze the equilibrium dynamics of disaggregate quantities and/or prices.

For the same reasons, there is no need to keep track of the cross-sectional distribution of households' consumption and asset holdings, ${ }^{20}$ and the two equations

$$
\begin{aligned}
& y_{t}=E_{t} y_{t+1}-\frac{1}{\sigma}\left(r_{t}-E_{t} \pi_{t+1}\right), \\
& \pi_{t}=\beta E_{t} \pi_{t+1}+\kappa\left(y_{t}-y_{t}^{N}\right),
\end{aligned}
$$

together with an interest rate rule, continue to characterize equilibrium dynamics of $\left\{y_{t}, \pi_{t}, r_{t}\right\}$ even after introducing heterogeneous households. The IS curve (13) can be derived by integrating the Euler equations (8) across households and using the resource constraint. The Phillips curve (14) has been introduced in Proposition 1.

As pointed out earlier, the effect of imperfect risk-sharing among households on aggregate dynamics is captured entirely by $\kappa$, an adjusted slope of the Phillips curve. Otherwise, the log-linearized reduced form of the model is exactly the same as the standard NK model. In particular, the transaction cost causes no change in the IS curve (13). This result may look somewhat peculiar because financial frictions have important first-order effects on the Euler equation of individual households. As can be seen in (8), the presence of financial frictions generates a direct effect of the current income on consumption while reducing the influence of the real interest rate. However, these effects on individual households' consumption behavior appear to wash out at the aggregate level in the current set-up.

This "wash-out" result for the aggregate Euler equation is due to the simplifying set-up of

\footnotetext{
${ }^{20}$ This statement does not hold when one introduces sectoral heterogeneity in price stickiness in addition to household heterogeneity as shown in Lee (2010).
} 
the model that makes consumption equal to output at the aggregate level (i.e. $c_{t} \equiv \int_{0}^{1} c_{t}(i) d i=$ $\left.y_{t}\right)$. Therefore, the result would not hold in general, for example if the model featured endogenous capital accumulation or non-zero government purchases. It is straightforward to show the aggregate Euler equation is generally given by

$$
c_{t}=E_{t} c_{t+1}-\frac{1}{\sigma(1+\omega)}\left(r_{t}-E_{t} \pi_{t+1}\right)+\frac{\omega}{1+\omega} E_{t}\left(y_{t}-y_{t+1}\right),
$$

which is reduced to (13) only if $c_{t}=y_{t}$.

Equation (15) resembles the aggregate Euler equation one can obtain in the alternative extension that adds rule-of-thumb consumers to NK models as in Gali, Lopez-Salido and Valles $(2004,2007)$ (henceforth GLV). To highlight the resemblance more clearly, I rewrite (15) as

$$
c_{t}=E_{t} c_{t+1}-\frac{1}{\sigma(1+\omega)}\left(r_{t}-E_{t} \pi_{t+1}\right)+\frac{\omega}{1+\omega}\left(h_{t}-E_{t} h_{t+1}\right)-\frac{\omega}{1+\omega} E_{t} \Delta a_{t+1},
$$

where $h_{t}=\int_{0}^{1} h_{t}(i) d i$ is aggregate hours. GLV showed that introducing rule-of-thumb consumers in a NK model makes aggregate consumption more responsive to the current labor income and hence helps account for the evidence on the positive consumption response to an exogenous increase in government spending. As can be seen in (16), the transaction cost explored here plays a similar role as rule-of-thumb consumers in GLV, and hence the current model has the potential to capture such evidence through the same mechanism as GLV's model.

While the two models have similar implications for the IS curve, the implications for the other key equation are different. The Phillips curve in GLV's model remains unchanged from the standard NK model because labors are homogeneous and hence the idiosyncratic income effect discussed in section 2.1 is absent. In contrast, the current model features heterogeneous labors, which increases price rigidities endogenously and flattens the Phillips curve as shown in Proposition 1. Note that this property enhances even further the current model's ability to 
account for the evidence on the consumption response to changes in government purchases, because sufficiently strong nominal rigidities, in addition to the positive impact of the current income on consumption, are also required to generate the positive consumption response as argued in GLV.

I will continue to assume that $c_{t}=y_{t}$ in the remainder of the paper to make the paper focused entirely on the one specific channel by which imperfect risk-sharing affects macroeconomic dynamics, highlighted in Proposition 1. Nevertheless, the discussion above reveals that a model with imperfect risk-sharing has the ability to produce richer dynamics than its perfect risk-sharing counterpart, because the presence of financial frictions, in principle, can affect not only the supply side (the Phillips curve) but also the demand side (the IS curve) of the economy in an important way.

\section{Consequences for the Frequency of Price Changes}

The main implication for aggregate output and the price of heterogenous households in the present set-up is clear from Proposition 1. Other things being equal, the response of inflation to exogenous shocks will be more muted, and consequently shocks will have larger and more persistent effects on the output gap in the imperfect risk-sharing economy.

The flip side of the above implication is that the degree of nominal rigidities required to explain the observed persistence and variability of the U.S. output gap and inertial aggregate inflation is reduced relative to the basic NK model. Proposition 1 suggests that one should expect the estimate of $\alpha$ will be smaller in the presence of financial frictions because the value of $\alpha$ required to explain any given value of $\kappa$, the slope of the Phillips curve, is lower the greater the degree of financial frictions.

Motivated by this implication, I investigate if the strategic complementarities contributed by household heterogeneity are strong enough to reconcile the long-standing inconsistency between macro and micro obervations on the frequency of price adjustments. To this end, I take some existing estimates of the slope parameter in the literature and back out the implied 
values of $\alpha$ under alternative assumptions on the degree of financial frictions.

I first rewrite the Phillips curve (14) as

$$
\pi_{t}=\beta E_{t} \pi_{t+1}+\kappa^{*} m c_{t},
$$

where $m c_{t}$ is the deviation of the log of average real marginal cost from its steady-state value and $\kappa^{*}=\kappa /\left(\sigma+\psi^{-1}\right)$. I use the alternative expression because previous studies that estimated NK Phillips curves often report the coefficient on marginal cost, $\kappa^{*}$, rather than $\kappa$. Based on the estimates in Gali and Gertler (1999); Gali, Gertler and Lopez-Salido (2001); Sbordone (2004); and more recently Smet and Wouters (2007); I consider three values for $\kappa^{*}$ : $0.2,0.3$ and 0.4 .

The slope, $\kappa^{*}$, contains four additional parameters, $\beta, \theta, \psi$ and $\sigma$, besides $\alpha$ and $\omega$. I therefore fix the first four parameters to back out the last two. I set $\beta$ to be $0.99, \psi$ to be 2 , and $\theta$ to be 6 , all of which are conventional values in business cycle models. As discussed in a previous section, the strength of the income effect on labor supply crucially depends on $\sigma$. I therefore consider some alternative values. Researchers often use relatively small values for $\sigma$ in the range of 1-4. But much larger values are also employed in the literature. In addition, the estimated $\sigma$ in a NK framework is often quite large. For example, Rabanal and Rubio-Ramirez (2005) estimated small-scale NK models similar to the one considered here and reported that the estimate of $\sigma$ is in the range of 4.5-8.3. Based on this observation, I take 3 as the benchmark value but also consider 2 and 4 to see the sensitivity of the results.

Figure 2 shows all possible combinations of $(\alpha, \omega)$ that are consistent with the three different values for $\kappa^{*}$ in the benchmark case. The figure confirms that the two parameters have an inverse relationship as anticipated. In addition, Table 1, 2 and 3 report the implied values of the duration of price contracts, $T=(1-\alpha)^{-1}$, under different degrees of risk-sharing and risk-aversion: $\omega$ and $\sigma$.

Overall, one can observe from the tables that the price stickiness endogenously delivered by imperfect risk-sharing is nontrivial, which enables the sticky-price model to capture persistent 
aggregate dynamics with a small degree of nominal rigidities that is consistent with micro-level empirical evidence. As an example, take the case that $\kappa^{*}=0.03$ from Table 1 . Under imperfect risk-sharing, the model implies that prices change every 1.97 quarters on average when $\omega=0.2$, which is broadly consistent with the microeconomic evidence recently documented in Bils and Klenow (2004). They reported that the median duration of prices is approximately between 4 and 6 months (or 1.33 and 2 quarters). In contrast, the average time between price changes is 3.47 quarters under perfect risk-sharing $(\omega=0)$. This implied duration is implausibly long in light of Bils and Klenow's evidence.

\section{Conclusion}

Most sticky-price models either rely on the representative-household abstraction, or equivalently assume perfect risk-sharing among households when they are heterogeneous in incomes. This paper has shown that the representative-household abstraction can lead to a substantial underestimation of the models' ability to propagate economic shocks. Apparently small frictions in risk-sharing can have a nontrivial impact on aggregate dynamics by increasing the degree of real rigidities through income effects on labor supply.

After constructing a stylized NK model with heterogeneous households and financial frictions, I conducted a simple quantitative exercise showing that real rigidities generated by household heterogeneity are sufficiently large and can improve the sticky-price models' consistency with micro-level empirical evidence on price adjustments.

The simplicity of the model allowed me to illustrate the mechanism analytically, which is the main focus of the current paper. An obvious trade-off is that the simplicity makes it difficult for one to take the model to data. Nevertheless, my analysis suggests the proposed mechanism is potentially important for the business cycle and encourages further quantitative studies with a more realistic set-up.

I conclude with a final note that the economic mechanism proposed in this paper generalizes to a "weaker" form of household heterogeneity. Even if labor markets were only segmented 
at a more aggregate level, as in the model with sector-specific labor markets in Carvalho and Lee (2011), the income effect would still work to deliver slower adjustments of the aggregate price level. ${ }^{21}$ More generally, this paper's main argument, that imperfect risk-sharing amplifies business cycle fluctuations in sticky-price models, would still hold as long as there are more than one labor market and households have less-than-full crossover capability.

\footnotetext{
${ }^{21}$ In the case of sector-specific labor markets, the income effect is captured by an endogenous shift term attached to Phillips curve, while the slope of the Phillips curve remains unaffected. To compute the endogenous shift term, one has to keep track of the distribution of households across sectors, which makes computation harder. See Lee (2010) for a detailed discussion.
} 


\section{References}

[1] Aiyagari, S. Rao. (1994) "Uninsured Idiosyncratic Risk and Aggregate Saving." Quarterly Journal of Economics, 109, 659-684.

[2] Altig, David, Lawrence Christiano, Martin Eichenbaum, and Jesper Linde. (2011) "FirmSpecific Capital, Nominal Rigidities and the Business Cycle." Review of Economic Dynamics, 14, 225-247.

[3] Attanasio, Orazio, and Steven Davis. (1996) "Relative wage movements and the distribution of consumption." Journal of Political Economy, 104, 1227-62.

[4] Ball, Laurence, and David Romer. (1990) "Real Rigidities and the Non-Neutrality of Money." Review of Economic Studies, 57, 183-203.

[5] Basu, Susanto. (1995) "Intermediate Goods and Business Cycles: Implications for Productivity and Welfare." American Economic Review, 85, 512-531.

[6] Bergin, Paul, and Robert Feenstra. (2000) "Staggered price setting, translog preferences, and endogenous persistence." Journal of Monetary Economics, 45, 657-680.

[7] Bernanke, Ben, Mark Gertler, and Simon Gilchrist. (1999) "The Financial Accelerator in a Quantitative Business Cycle Framework." In John Taylor and Michael Woodford (eds.), The Handbook of Macroeconomics, 1C, 1341-1397, Elsevier, New York.

[8] Bils, Mark, and Pete Klenow. (2004) "Some Evidence on the Importance of Sticky Prices," Journal of Political Economy, 112, 947-985.

[9] Calvo, Guillermo. (1983) "Staggered Prices in a Utility-Maximizing Framework," Journal of Monetary Economics, 12, 983-998.

[10] Carvalho, Carlos. (2006) "Heterogeneity of Price Stickiness and the Real Effects of Monetary Shocks." The BE Journal of Macroeconomics Vol. 2, Iss. 1. 
[11] Carvalho, Carlos, and Jae Won Lee (2011), "Sectoral Price Facts in a Sticky-Price Model." unpublished.

[12] Chari, V.V., Patrick J. Kehoe, and Ellen R. McGrattan. (2000) "Sticky Price Models of the Business Cycle: Can the Contract Multiplier Solve the Persistence Problem?" Econometrica, 68, 1151-1179.

[13] Christiano, Lawrence, Martin Eichenbaum, and Charles Evans. (2005) "Nominal Rigidities and the Dynamic Effects of a Shock to Monetary Policy." Journal of Political Economy, 113,1-45.

[14] Dixit, Avinash K., and Joseph E. Stiglitz. (1977) "Monopolistic Competition and Optimum Product Diversity." American Economic Review, 67, 297-308.

[15] Fisher, Jonas, and Martin Eichenbaum. (2007) "Estimating the Frequency of Price Reoptimization in Calvo Style Pricing Models with Dynamic Indexation." Journal of Monetary Economics, 54, 2032-2047.

[16] Gali, Jordi. (2008) Monetary Policy, Inflation and the Business Cycle: An Introduction to the New Keynesian Framework, Princeton University Press.

[17] Gali, Jordi, and Mark Gertler. (1999) "Inflation Dynamics: A Structural Econometric Analysis." Journal of Monetary Economics 44, 195-222

[18] Gali, Jordi, Mark Gertler, and J. David Lopez-Salido. (2001) "European Inflation Dynamics." European Economic Review 45, 1237-1270.

[19] Gali, Jordi., J. David Lopez-Salido, and Javier Valles. (2004) "Rule-of-Thumb consumers and the Design of Interest Rate Rules." Journal of Money, Credit, and Banking 36, 739-764. 
[20] Gali, Jordi., J. David Lopez-Salido, and Javier Valles. (2007) "Understanding the Effects of Government Spending on Consumption." Journal of the European Economic Association 5, 227-270.

[21] Goodfriend, Marvin, and Robert King. (1997) "The New Neoclassical Synthesis and the Role of Monetary Policy." National Bureau of Economic Research Macroeconomics Annual, 231-283.

[22] Hayashi, Fumio, Joseph Altonji, and Laurence Kotlikoff. (1996) "Risk-Sharing between and within Families." Econometrica, 64, 261-294.

[23] Heathcote, Jonathan, and Fabrizio Perri. (2002) "Financial Autarky and International Real Business Cycles." Journal of Monetary Economics 49, 601-627.

[24] Heathcote, Jonathan, and Kjetil Storesletten, and Giovanni Violante. (2009) "Quantitative Macroeconomics with Heterogeneous Households." Annual Review of Economics 1, 319-354

[25] Huggett, Mark. (1993) "The Risk-Free Rate in Heterogeneous-Agents, Incomplete Markets Economies." Journal of Economic Dynamics and Control 17, 953-969.

[26] Kimball, Miles. (1995) "The Quantitative Analytics of the Basic Neomonetarist Model." Journal of Money, Credit and Banking 27, 1241-1277.

[27] King, Robert, Charles Plosser, and Sergio Rebelo. (1998) "Production, Growth and Business Cycles: I. the Basic Neoclassical Model." Journal of Monetary Economics 21, 195232.

[28] Krusell, Per and Anthony Smith, Jr. (1998) "Income and Wealth Heterogeneity in the Macroeconomy." Journal of Political Economy 106, 867-896.

[29] Kydland Finn, and Edward Prescott. (1982) "Time to build and aggregate fluctuations." Econometrica 50, 1345-70. 
[30] Lee, Jae Won. (2010) "Heterogeneous Households, Real Rigidity, and Estimated Duration of Price Contracts in a Sticky Price DSGE Model." unpublished.

[31] Nakamura, Emi, and Jon Steinsson (2008), "Five Facts About Prices: A Reevaluation of Menu Cost Models." Quarterly Journal of Economics, 123, 1415-1464.

[32] Nelson, Julie. (1994) "On Testing for Full Insurance Using Consumer Expenditure Survey Data." Journal of Political Economy 102, 384-394.

[33] Rabanal, Pau and Juan Rubio-Ramirez. (2005) "Comparing New Keynesian Models of the Business Cycle: A Bayesian approach." Journal of Monetary Economics 52, 11511166.

[34] Sbordone, Argia. (2004), "Do Expected Future Marginal Costs Drive Inflation Dynamics?" unpublished.

[35] Schmitt-Grohe, Stephanie, and Martin Uribe (2003) "Closing Small Open Economy Models." Journal of International Economics 61, 163-185.

[36] Schulhofer-Wohl, Sam. (2010) "Heterogeneity and Tests of Risk Sharing." unpublished.

[37] Sims, Christopher A. (2001) "Solving Linear Rational Expectation model." Computational Economics 20, 1-20.

[38] Smets, Frank, and Raf Wouters. (2003) "An Estimated Dynamic Stochastic General Equilibrium Model of the Euro Area" Journal of European Economic Association, 1, $1123-1175$.

[39] Smets, Frank, and Raf Wouters. (2007) "Shocks and Frictions in US Business Cycles: A Bayesian DSGE Approach." American Economic Review 97, 586-606.

[40] Walsh, Carl. (2003) Monetary Theory and Policy, The MIT Press

[41] Woodford, Michael. (2003) Interest and Prices: Foundations of a Theory of Monetary Policy, Princeton University Press. 
[42] Woodford, Michael. (2005) "Firm-Specific Capital and the New-Keynesian Phillips Curve." International Journal of Central Banking 1, 1-46.

[43] Yun, Tack. (1996) "Nominal Price Rigidity, Money Supply Endogeneity, and Business Cycles." Journal of Monetary Economics 37, 345-370. 


\section{Appendix}

\section{A Tables and Figures}

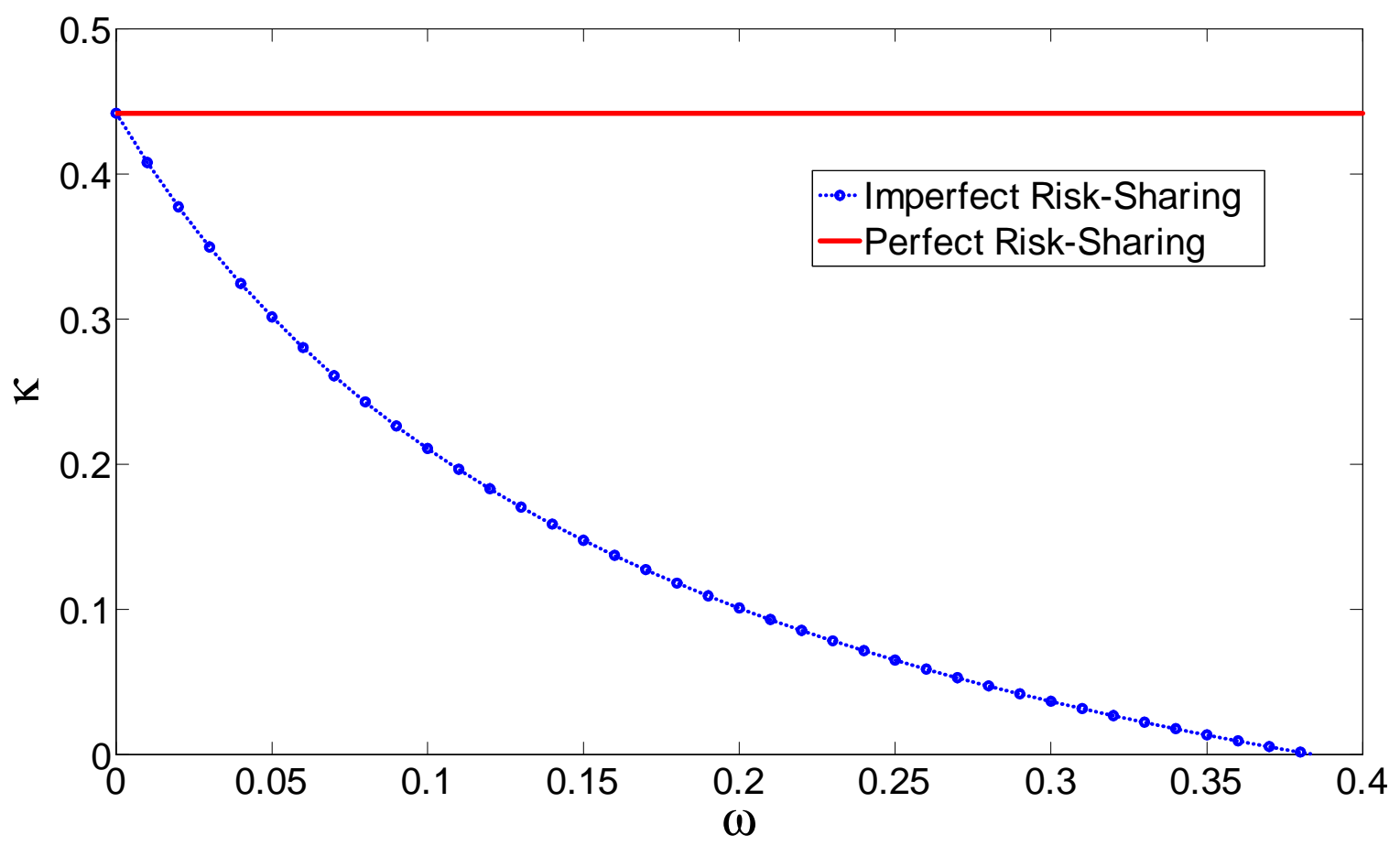

Figure 1: Slope of Phillips curve 


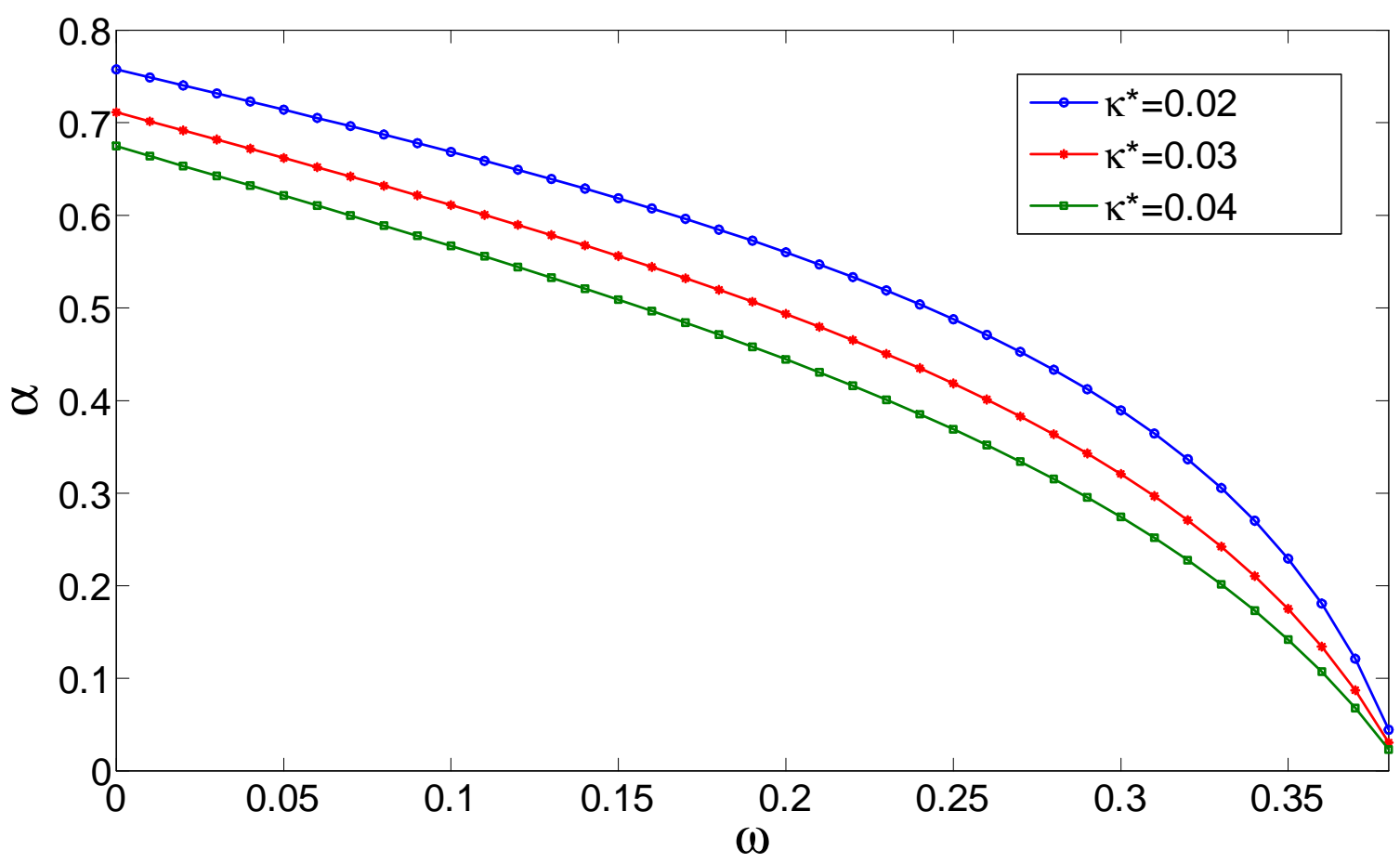

Figure 2: Implied values of $\alpha$ and $\omega$ from $\kappa^{*}$ 
Table 1: Implied values of $T$

\begin{tabular}{|c|c|c|c|c|}
\hline \multirow[b]{3}{*}{$\kappa^{*}$} & \\
\hline & Perfect Risk-Sharing & Imper & ect Risk-s & haring \\
\hline & $\omega=0$ & $\omega=0.15$ & $\omega=0.2$ & $\omega=0.25$ \\
\hline 0.02 & 4.13 & 2.62 & 2.27 & 1.95 \\
\hline 0.03 & 3.47 & 2.25 & 1.97 & 1.72 \\
\hline 0.04 & 3.08 & 2.04 & 1.80 & 1.59 \\
\hline
\end{tabular}

Table 2: Implied values of $T$

\begin{tabular}{cccccc} 
& \multicolumn{3}{c}{$\sigma=4$} & \multicolumn{3}{c}{ Imperfect Risk-Sharing } \\
\cline { 2 - 2 } \cline { 5 - 6 }$\kappa^{*}$ & Perfect Risk-Sharing & & $\omega=0.15$ & $\omega=0.2$ & $\omega=0.25$ \\
0.02 & $\omega=0$ & & 2.20 & 1.73 & 1.19 \\
0.03 & 3.13 & & 1.92 & 1.54 & 1.13 \\
0.04 & 3.47 & & 1.75 & 1.44 & 1.10
\end{tabular}

Table 3: Implied values of $T$

\begin{tabular}{cccccc}
\multicolumn{3}{c}{$\sigma=2$} & \multicolumn{3}{c}{} \\
& Perfect Risk-Sharing & & \multicolumn{2}{c}{ Imperfect Risk-Sharing } \\
\cline { 2 - 2 } \cline { 5 - 6 }$\kappa^{*}$ & $\omega=0$ & & $\omega=0.15$ & $\omega=0.2$ & $\omega=0.25$ \\
0.02 & 4.13 & & 3.06 & 2.81 & 2.59 \\
0.03 & 3.47 & & 2.60 & 2.41 & 2.23 \\
0.04 & 3.08 & 2.34 & 2.17 & 2.02
\end{tabular}




\section{B Derivation of (9)}

From (6) one can derive the following equation:

$$
c_{t}^{R}(i)-\frac{\phi}{\sigma+\phi} x_{t}^{R}(i)=c_{t+1}^{R}(i)-\frac{\phi}{\sigma+\phi} x_{t+1}^{R}(i),
$$

which must hold for every time period $t$ and for every state of the economy. The equation (17) implies that $c_{t}^{R}(i)-\frac{\phi}{\sigma+\phi} x_{t}^{R}(i)$ should be constant. Let

$$
c_{t}^{R}(i)-\frac{\phi}{\sigma+\phi} x_{t}^{R}(i)=z
$$

for some constant $z$. Then it is necessary that $z=0$ because $\int_{0}^{1} c_{t}^{R}(i) d i=\int_{0}^{1} x_{t}^{R}(i) d i=0$.

\section{Proof of Proposition 1}

Log-linearizing a firm's first order condition (12) gives:

$$
\begin{aligned}
& E_{t} \sum_{k=0}^{\infty}(\alpha \beta)^{k}\left[p_{t}^{*}(i)-p_{t+k}\right]=E_{t} \sum_{k=0}^{\infty}(\alpha \beta)^{k}\left[w_{t+k}(i)-a_{t+k}-p_{t+k}\right] \\
&=E_{t} \sum_{k=0}^{\infty}(\alpha \beta)^{k}\left[\psi^{-1} h_{t+k}(i)+\sigma c_{t+k}(i)-a_{t+k}\right] \\
&=E_{t} \sum_{k=0}^{\infty}(\alpha \beta)^{k}\left[\psi^{-1} y_{t+k}(i)+\sigma c_{t+k}(i)-\left(1+\psi^{-1}\right) a_{t+k}\right] \\
&=E_{t} \sum_{k=0}^{\infty}(\alpha \beta)^{k}\left[\psi^{-1} y_{t+k}^{R}(i)+\sigma c_{t+k}^{R}(i)+\left(\sigma+\psi^{-1}\right) y_{t+k}-\left(1+\psi^{-1}\right) a_{t+k}\right]
\end{aligned}
$$

The household's intra-temporal first order condition can be log-linearized as:

$$
w_{t}(i)-p_{t}=\psi^{-1} h_{t}(i)+\sigma c_{t}(i)
$$


which can be written as:

$$
w_{t}^{R}(i)=\psi^{-1} h_{t}^{R}(i)+\sigma c_{t}^{R}(i)
$$

Adding $h_{t}^{R}(i)\left(=y_{t}^{R}(i)\right)$ to both sides yields:

$$
w_{t}^{R}(i)+h_{t}^{R}(i)=\left(1+\psi^{-1}\right) y_{t}^{R}(i)+\sigma c_{t}^{R}(i)
$$

Note that one can obtain a log-linearized relationship between relative total income and relative labor income, $x_{t}^{R}(i)=\left(\frac{\theta}{\theta-1}\right)\left[w_{t}^{R}(i)+h_{t}^{R}(i)\right]$ from the definition of total income, $X_{t}(i) \equiv \frac{W_{t}(i) H_{t}(i)+\Pi_{t}-P_{t} T_{t}}{P_{t}}$, and also $c_{t}^{R}(i)=\frac{\omega}{1+\omega} x_{t}^{R}(i)$ from (10). Combining these two and then using the household's intra-temporal first order condition gives:

$$
c_{t}^{R}(i)=\frac{\omega}{1+\omega} \frac{\theta}{\theta-1}\left[w_{t}^{R}(i)+h_{t}^{R}(i)\right]=\frac{\omega}{1+\omega} \frac{\theta}{\theta-1}\left[\left(1+\psi^{-1}\right) y_{t}^{R}(i)+\sigma c_{t}^{R}(i)\right],
$$

which can be solved for $c_{t}^{R}(i)$ as:

$$
c_{t}^{R}(i)=\gamma y_{t}^{R}(i)
$$

where

$$
\gamma \equiv \frac{1+\psi^{-1}}{\frac{\theta-1}{\theta} \frac{1+\omega}{\omega}-\sigma}
$$

Substituting (19) into (18), I rewrite the log-linearized first order condition as:

$E_{t} \sum_{k=0}^{\infty}(\alpha \beta)^{k}\left[p_{t}^{*}(i)-p_{t+k}\right]=E_{t} \sum_{k=0}^{\infty}(\alpha \beta)^{k}\left[\left(\psi^{-1}+\sigma \gamma\right) y_{t+k}^{R}(i)+\left(\sigma+\psi^{-1}\right) y_{t+k}-\left(1+\psi^{-1}\right) a_{t+k}\right]$, 
I then substitute the log-linearized demand function, $y_{t+k}^{R}(i)=-\theta\left[p_{t}^{*}(i)-p_{t+k}\right]$, into $(20)$, which gives:

$$
\left(1+\theta\left(\psi^{-1}+\sigma \gamma\right)\right) E_{t} \sum_{k=0}^{\infty}(\alpha \beta)^{k}\left[p_{t}^{*}(i)-p_{t+k}\right]=\left(\sigma+\psi^{-1}\right) E_{t} \sum_{k=0}^{\infty}(\alpha \beta)^{k}[\underbrace{y_{t+k}-(21)}_{=y_{t+k}-y_{t+k}^{N}}]
$$

Finally, it is straightforward to obtain the Phillips curve from (21) following the standard steps:

$$
\pi_{t}=\beta E_{t} \pi_{t+1}+\kappa\left(y_{t}-y_{t}^{N}\right)
$$

where

$$
\kappa=\left\{\frac{(1-\alpha)(1-\alpha \beta)}{\alpha}\right\}\left\{\frac{\sigma+\psi^{-1}}{1+\theta\left(\psi^{-1}+\sigma \gamma\right)}\right\} .
$$

